\title{
Jogo das cores: uma atividade interativa no Ensino Fundamental
}

\author{
Play of colors: an interactive activity in fundamental education \\ Juego de colores: una actividad interactiva en la educación fundamental
}

Edemar Benedetti Filho (edemar@ufscar.br)

Universidade Federal de São Carlos-UFSCar.

Letícia Asheley Gomes (leticia.asheley.gomes@gmail.com)

Universidade Federal de São Carlos-UFSCar.

Gabriel Moraes Reche Martins (gmreche1999@gmail.com)

Universidade Federal de São Carlos-UFSCar.

João Marcos Soares Maia (joaomarcossoaresmaia@hotmail.com)

Universidade Federal de São Carlos-UFSCar.

Resumo: Este trabalho teve como objetivo o desenvolvimento e aplicação de um jogo didático, envolvendo conceitos básicos referentes à teoria das cores. O jogo foi concebido para alunos do Ensino Fundamental II, a partir de uma temática para os conteúdos que estavam sendo trabalhados em sala de aula pelo docente da disciplina de Ciências. O jogo, chamado "Cores", pedagogicamente permitiu revisar, de forma lúdica no Clube de Ciências, a temática sobre a composição das cores propiciando aos alunos um processo de ensino e de aprendizagem mais prazeroso, e como divulgação científica, a atividade foi aplicada para os participantes da Feira de Ciências. Através de uma metodologia qualitativa o docente da turma do $6^{\circ}$ ano relatou que a revisão dos conceitos foi altamente satisfatória para o processo de consolidação da aprendizagem, e inclusive a exploração de habilidades de socialização que a proposta apresentou, foi elogiada pelo corpo docente da escola. Os alunos que participaram da atividade demonstraram grande aceitação por essa metodologia alternativa e solicitaram sua aplicação para outras turmas na escola.

Palavras-chave: Teoria das cores; Atividades lúdicas; Jogos.

Abstract: This work aimed to develop and apply a didactic game, involving basic concepts related to color theory. The game was designed for Elementary School students, based on a theme for the contents that were being worked on in the classroom by the teacher of the Science discipline. The game, called "Cores", pedagogically allowed to revise, in a playful way at the Science Club, the theme about the composition of colors providing students with a more pleasant teaching and learning process, and as a scientific dissemination, the activity was applied to Science Fair participants. Through a qualitative methodology the 6th year class teacher reported that the revision of the 
concepts was highly satisfactory for the process of consolidating learning, and even the exploration of socialization skills that the proposal presented, was praised by the school faculty. The students who participated in the activity showed great acceptance for this alternative methodology and requested its application to other classes in the school.

Keywords: Color theory; Playful activities; Games.

Resumen: Este trabajo tuvo como objetivo desarrollar y aplicar un juego didáctico, involucrando conceptos básicos relacionados con la teoría del color. El juego fue diseñado para estudiantes de Educación Primaria, basado en una temática de los contenidos que se estaban trabajando en el aula por parte del docente de la disciplina de Ciencias. El juego, denominado "Cores", permitió revisar pedagógicamente, de forma lúdica en el Club de Ciencias, la temática sobre la composición de colores proporcionando a los estudiantes un proceso de enseñanza y aprendizaje más ameno, y como divulgación científica, la actividad se aplicó a Participantes de la Feria de Ciencias. Mediante una metodología cualitativa el docente de sexto año informó que la revisión de los conceptos fue altamente satisfactoria para el proceso de consolidación del aprendizaje, e incluso la exploración de las habilidades de socialización que presentaba la propuesta, fue elogiada por el profesorado de la escuela. Los alumnos que participaron de la actividad mostraron gran aceptación por esta metodología alternativa y solicitaron su aplicación a otras clases de la escuela.

Palabras-clave: Teoría del color; Actividades lúdicas; Juegos.

\section{INTRODUÇÃO}

\section{1/Jogo e aprendizagem}

O Ensino de Ciências, especialmente a Física e a Química, tem sido um dos maiores desafios aos educadores no tocante a sua aprendizagem e no despertar ao interesse dos alunos por estas disciplinas. O seu baixo estímulo é um dos fatores que contribui para a maioria dos alunos não compreenderem as teorias e os conceitos descritos nas Ciências. A relação desconexa dos assuntos tratados na sala de aula com a realidade do estudante também contribui para sua desmotivação. A metodologia de ensino praticada pelo docente, na maioria das vezes utilizando apenas a forma tradicional, faz com que a Ciência seja tratada de maneira puramente matemática, sem desafios lógicos aos alunos e, raramente, traz situações do dia a dia como exemplo, sem a utilização de um raciocínio significativo para os alunos, como por exemplo, a descoberta de resoluções aos problemas reais que o uso das suas teorias pode proporcionar. 
Esta realidade sobre a aprendizagem em Ciências faz com que ela seja cansativa e desinteressante, a falta de motivação é um dos fatores que levam a esse desinteresse pelas disciplinas, fazendo com que o estudante não compreenda a importância da Ciência para a sua formação científica e cidadã. $O$ desinteresse geralmente está relacionado com as dificuldades de aprendizagem apresentadas pelos alunos, onde o muitas vezes, um desenvolvimento pedagógico cansativo e desmotivador para os alunos principalmente quando iniciam estes estudos no ambiente escolar".

De acordo com Krasilchik (2008) é necessário que os alunos nos diversos níveis de aprendizagem possam estar aptos para empregar o conhecimento adquirido para as tomadas de decisões tanto individual quanto coletivas, prezando pelo respeito com seus pares e com o meio em que está inserido. Este desafio faz parte das habilidades práticas dos docentes em apresentar aos alunos mecanismos para que sua aprendizagem ocorra dentro destes objetivos, buscando assim melhorar os resultados negativos que constantemente são retratados nas revistas científicas com relação ao baixo interesse e desempenho dos discentes (COSTA; DUARTE; GAMA, 2020).

É diante destas perspectivas que os docentes têm um papel essencial na mediação no processo científico, não apenas descrevendo os conceitos científicos, mas fazendo com que os alunos possam participar dessa construção, levar aos alunos estratégias metodológicas que sejam participativas. É nesse sentido, que consideramos os jogos didáticos e/ou educativos, como instrumentos metodológicos que podem auxiliar nesta dinâmica de aprendizagem e obter os resultados desejados (ALVES; COSTA; SOUSA, 2020).

O jogo educativo é aquele que está relacionado aos aspectos educacionais, possui uma propriedade que não se enquadra em toda a definição do termo jogo filosófico. Segundo Brougère (2002) o jogo educativo necessariamente pode não ser classificado como tal, mas apresentar diversas características inerentes que o relaciona ao jogo filosófico no sentido stricto sensu. De acordo com Soares (2015), a fundamentação da relação lúdica em aprimorar o desenvolvimento cognitivo do aluno, faz com que esta atividade possa ser denominada de jogo educativo, possuindo relação equilibrada entre o jogo e a educação. Estas considerações são confirmadas na definição de Kishimoto (1994), na qual o jogo educativo é como uma situação ou uma ferramenta pedagógica 
em que o docente consegue explorar, no ambiente escolar, as habilidades dos alunos com relação a conteúdos específicos das disciplinas ministradas (BENEDETTI-FILHO; BENEDETTI, 2015).

Para-Leite e Soares (2020),

[...] o jogo educativo é aquele que pode ser utilizado para ensinar algo a alguém, não necessariamente conteúdos escolares. Tal definição se coaduna com o que preconiza Brougère (2002). Já o jogo educativo formalizado (JEF) é aquele jogo utilizado para ensinar conceitos em ambientes formais de ensino, ou seja, o jogo utilizado em sala de aula propriamente dito (LEITE; SOARES, 2020, p. 228).

Assim, o jogo educativo formalizado, ainda pode ser mais bem interpretado definindo em dois segmentos, o jogo didático e o jogo pedagógico, que diferem entre si através das suas propostas metodológicas. O jogo pedagógico é empregado pelo docente para inserir novos conteúdos didáticos, nos quais não foram discutidos anteriormente, e em relação ao jogo educativo ele é utilizado como reforço ou avaliação dos conteúdos já ministrados pelo docente em sala de aula.

\section{$1.2 \mathrm{~A}$ cor}

A civilização sempre atribuiu um caráter mágico envolvendo as cores, independente de sua época ela ainda continua a ter um papel importante em nossa sociedade (GUIMARÃES, 2002). A cor não apresenta uma existência material, é somente uma sensação que nós sofremos através de certas organizações nervosas no globo ocular, que sofre mudanças sob a ação da luz, nosso órgão da visão. Segundo Pedrosa (1989), os estímulos nos quais as sensações cromáticas estão presentes no processo da visão, são formados por dois grupos, estes relacionados com as definições físicas para o comportamento da luz, são: as cores-luz e as cores-pigmento. A primeira é formada pela radiação luminosa visível através da síntese aditiva para a luz branca, semelhante à luz proveniente do sol, reunindo de forma equilibrada as matizes que compõe a sua natureza. Por outro lado, a cor-pigmento é a luz refletida ou refratada pelos corpos a partir, geralmente, dos raios solares, e após a sua observação sobre o corpo material, é a luz difundida que podemos observar e que nos representa então as cores dos materiais.

De todo o espectro da luz, o órgão humano da visão pode alcançar somente uma pequena faixa, que compreende entre os raios infravermelhos e os raios ultravioleta. 
Esta pequena faixa está entre o comprimento de onda de 700 nanômetros (vermelho) até o de 400 nanômetros (violeta), a figura 1 ilustra a faixa para a luz visível pelo olho humano.

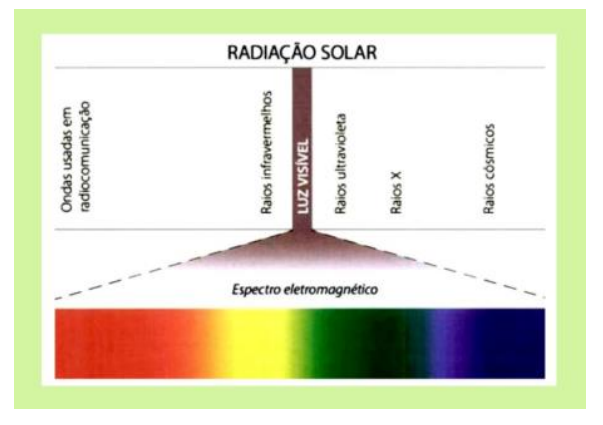

Figura 1 - Espectro eletromagnético da luz visível a partir da radiação solar.

Fonte: Próprios autores.

Dependendo do nível de incidência de luz em nossos olhos, veremos os objetos mais ou menos iluminados. Assim, além das cores visíveis, temos suas nuanças em relação à luminosidade. Nossa percepção em relação às cores está presente em três características:

a) Matiz: que tem relação com o comprimento de onda do feixe luminoso, é a gradação das cores (o amarelo do azul, o verde do violeta, etc);

b) Brilho: o valor de luminosidade, da intensidade das cores, é a escala do claro ao escuro de uma cor em relação a uma escala no tom de cinza e que tem uma variação do branco ao preto;

c) Croma: representa a saturação das cores, é a pureza relativa de uma escala no tom de cinzas, e quanto tem sua intensidade máxima, a cor predominante é considerada pura.

Este conjunto de características é que nos representa as cores para os objetos, por exemplo, vemos um objeto vermelho, pela capacidade que este corpo tem em absorver quase todos os raios que compõe a luz branca (todas as cores) que o atinge e refletir para a sua volta somente à cor vermelha. Segundo Kandinsky, um estudioso sobre o tema propôs a divisão de todas as cores do espectro em dois grupos: as cores quentes e frias, e as cores claras e escuras (BARROS, 2007). 
As cores são classificadas como primárias e secundárias, e em básicas e complementares. As cores primárias são aquelas que não podem ser formadas por nenhuma mistura de cores, sendo elas o azul-avioletado, o verde e o vermelho, e também não podem ser decompostas. Também é denominada de cor geratriz, pois através de proporções variáveis de suas misturas, é possível compor todas as cores do espectro visível. Quando ocorre a mistura proporcional para estas três cores, e nas luzes coloridas, há produção da cor branca. Quando ocorre a soma destas cores, o fenômeno recebe a denominação de síntese aditiva, a figura 2 ilustra as cores primárias e a sua síntese.
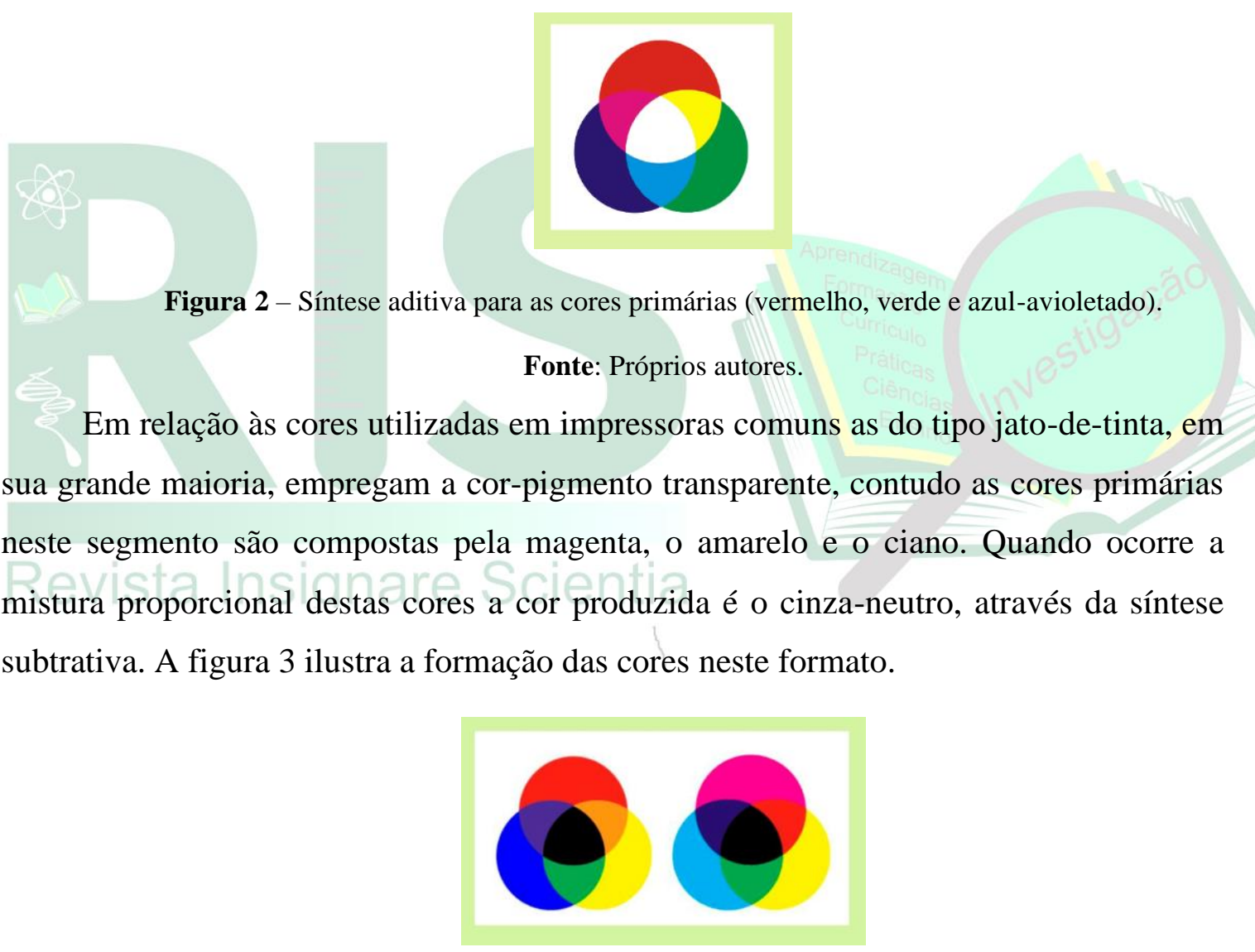

Figura 3 - Ilustração para as cores-pigmentos opacas e transparentes para a formação das cores.

Fonte: Próprios autores.

As cores secundárias são formadas a partir da combinação de duas cores primárias, e por este motivo não são puras. As cores possíveis são: o laranja, o roxo e o verde, por exemplo, a união proporcionais das cores primárias azul e amarelo produz o verde, como também ilustrado na figura 3. As cores complementares foram adotadas 


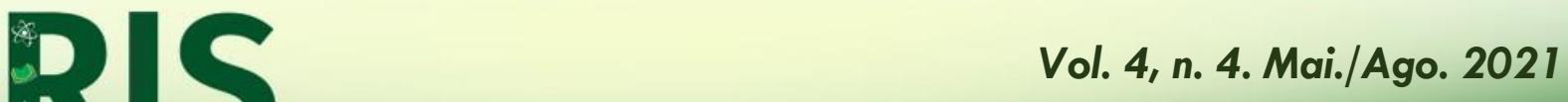

ISSN: 2595- 4520

pela área da Física para propor uma nomenclatura universal com relação às teorias das cores. A figura 4 ilustra um esquema que representa esta definição (FARINA, 1986).

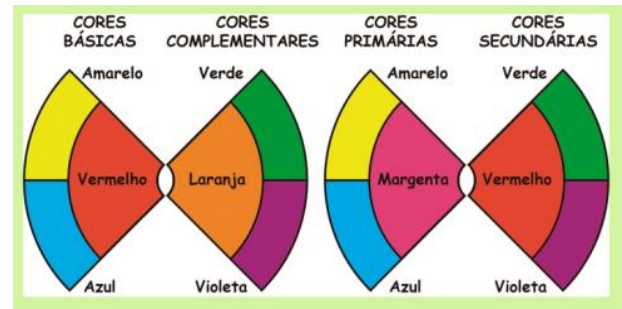

Figura 4 - Representação adaptada de Farina (1986) para as cores básicas, complementares, primárias e secundárias.

Fonte: Próprios autores.

O objetivo desta pesquisa foi desenvolver uma atividade lúdica na forma de um jogo de tabuleiro denominado de "Cores", envolvendo os conceitos referentes à teoria das cores, para alunos do $6^{\circ}$ Ano no ciclo II do Ensino Fundamental, como uma ferramenta metodológica para a divulgação científica e a revisão dos conceitos discutidos pelo professor. Além de proporcionar aos alunos uma forma de interação social, principalmente nas discussões para as tomadas de decisões do grupo em relação ao pensamento lógico para a resolução dos problemas durante as partidas da atividade lúdica.

\section{METODOLOGIA}

\subsection{Confecção do jogo}

O jogo "Cores" foi produzido através da impressão em papel opaline A4 com gramatura de $180 \mathrm{mg} / \mathrm{cm} 2$ por uma impressora jato de tinta colorida. O jogo é composto por 4 tabuleiros para marcações das composições das cores, 40 cartas de cores, 10 cartas de efeitos, e 300 peças (tolkens) para as cores primárias, secundárias, terciárias e suas nuanças de tons de preto. A figura 5 ilustra alguns desses componentes para o jogo "Cores". As cartas depois de impressas foram recortadas, e o fundo e frente foram unidos, em seguida plastificadas para um melhor manuseio pelos jogadores e durabilidade. 


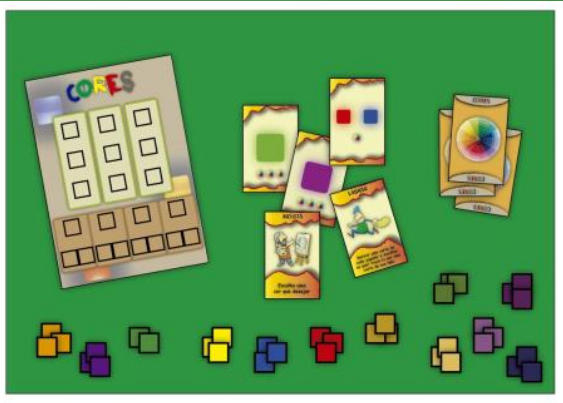

Figura 5 - Ilustração para alguns componentes que compõe o jogo “Cores”.

Fonte: Próprios autores.

\subsection{Regras}

O jogo tem como objetivo chegar primeiro no fim do tabuleiro, da parte inferior para a parte superior através da composição das cores do círculo cromático, e assim ser o vencedor da partida.

As cartas de cores, efeito, pretas e brancas são embaralhadas e organizadas em uma pilha de compras. Cada jogador (ou grupo) recebe ao início 5 cartas e é decidido por meio de sorteio quem joga primeiro seguindo em sentido anti-horário. O tabuleiro é percorrido da borda inferior à borda superior.

O jogo se inicia com o jogador podendo fazer alguns movimentos: pode trocar uma carta de cor primária pela cor correspondente de uma peça e colocar no seu tabuleiro em qualquer espaço da fileira inferior do bloco marrom; ou utilizar uma das cartas de efeito caso tenha, lendo-a e descartando a mesma após o uso; ou descartar uma carta em uma pilha de descarte sem o seu uso e comprar outra carta da pilha de compra. Quando a carta de efeito é utilizada e descartada deve-se retirar uma nova carta do monte de compras. Ou seja, sempre cada jogador (ou equipe) deve ter 5 cartas em sua mão. Encerra-se o turno do primeiro jogador é iniciado o turno do jogador à direita o qual pode realizar as mesmas ações descritas anteriormente. É importante lembrar que o turno só pode ser encerrado se todos os jogadores possuem as cinco cartas na mão.

Com a adição de duas cores primárias no bloco marrom, pode ser feita a adição de uma cor secundária no espaço único no topo do bloco marrom da mesma forma que ocorreu com a cor primária. Com a adição de uma cor secundária, pode ser adicionada 
uma cor terciária derivada da mesma na base inferior do bloco claro. Segue-se nesse bloco com a adição de uma peça preta ou branca que irá decidir se a última peça será uma tonalidade mais clara ou escura da cor terciária. Cabe lembrar que as cores são sempre correspondentes à teoria das cores e devem ser as uniões delas para a composição das cores secundárias, terciárias e a nuança de tom de cinza. Ganha o jogador que chegar primeiro ao fim do tabuleiro.

Descrição para as cartas de efeito:

Artista - O jogador pode escolher uma cor para colocar diretamente no tabuleiro.

Atleta - O jogador pode pegar duas cartas da pilha de compra e deve descartar duas cartas da sua mão (além da própria carta).

Bomba - O jogador pode retirar, caso tenha, uma cor de cada adversário.

Desastrado - O jogador deve retirar uma cor do seu próprio tabuleiro caso tenha.

Dorminhoco - O jogador escolhe uma pessoa para ficar uma rodada sem jogar.

Ladrão - O jogador retira uma carta de cada jogador (a carta é escolhida sem poder ver as outras cartas) e pode trocar uma delas por uma de sua mão. As cartas são descartadas e cada jogador completa a sua mão até cinco cartas.

Mágico - O jogador pode trocar uma carta da sua mão com uma carta da pilha de descartes (além da própria carta).

Nerd - O jogador pode escolher uma carta qualquer do baralho de efeito para colocar na sua mão.

Observador - O jogador pode olhar as três cartas do topo da pilha de compra e colocar uma delas na sua mão. As outras duas cartas devem ser embaralhadas novamente na pilha de compra.

Saltador - O jogador à direita de quem usou a carta perde a vez de jogar.

\subsection{Aplicação da atividade}

O jogo "Cores" foi aplicado em uma Escola Municipal de uma cidade do interior do Estado de São Paulo, com alunos do $6^{\circ}$ ano do Ensino Fundamental II. Sua aplicação se deu em dois momentos distintos, no Clube de Ciências e na Feira de Ciências, estas atividades foram organizadas por bolsistas do Programa Institucional de Bolsas de Iniciação à Docência (PIBID).

A obtenção de dados para análise envolvendo a pesquisa ocorreu através do emprego de entrevistas e anotações em diário de campo, fornecendo os dados qualitativos sobre a interação dos alunos a respeito da atividade. A coleta e análise dos dados, obtidos a partir dessa atividade lúdica pedagógica, apoiou-se nas ideias de Godoy (1995), no qual descreve sobre a pesquisa qualitativa, como a interação entre o pesquisador (entrevistador) e os alunos (entrevistados) tem uma forte relação com a construção da realidade que trabalha com o universo de crenças, valores, significados, e que estes não podem ser reduzidos a uma simples operação de variáveis: 
O ambiente é uma fonte direta dos dados e o pesquisador como instrumento chave; possui caráter descritivo; o processo é o foco principal de abordagem e não o resultado ou o produto; a análise dos dados foi realizada de forma intuitiva e indutivamente pelo pesquisador; não requereu o uso de técnicas e métodos estatísticos; e, por fim, teve como preocupação maior a interpretação de fenômenos e a atribuição de resultados (GODOY, 1995, p. 58).

As observações comportamentais dos alunos durante a aplicação da atividade foram registradas por meio de diário de campo, e puderam receber a análise dos dados através de uma abordagem qualitativa segundo as recomendações de Bogdan e Biklen (2000). Para verificar a importância destas observações comportamentais foi seguido as instruções recomendadas por Mello (2011, p. 76):

[...] a pesquisa qualitativa é um tipo de pesquisa onde o pesquisador pode ser o interpretador de uma realidade, sendo capaz de descrever fenômenos e comportamentos além de fazer citações diretas de pessoas envolvidas na pesquisa e interagir com indivíduos, grupos e organizações.

A aplicação no Clube de Ciências ocorreu com a formação de grupos aos alunos participantes no período do contra turno, pois a escola teve ensino integral. Neste momento houve a participação de 20 alunos. Na aplicação da atividade quando ocorreu a Feira de Ciências, foram montadas algumas mesas com os tabuleiros e estes eram utilizados pelos participantes da feira, sem o rigor quanto à série cursada. Participaram neste momento cerca de 40 alunos, englobando o ciclo I e II para o ensino fundamental.

Para manter 0 anonimato dos participantes seus nomes foram substituídos por aluno 1 a 20, para os participantes do $6^{\circ}$ Ano no Clube de Ciências e de 21 a 60 para o público da Feira de Ciências. Todas as aplicações tiveram a aprovação da direção da escola, do acompanhamento pedagógico e do professor da disciplina, também em todo o momento houve a presença do professor da disciplina de Ciências nos momentos das interações com os alunos para as coletas dos dados durante a pesquisa e seus registros em diário de campo.

\section{RESULTADOS E DISCUSSÃO}

A proposta foi desenvolvida tendo como princípio a interação que o Clube de Ciências propicia aos alunos, sendo este um espaço de ensino e aprendizagem não formal, isto é, temas de livre escolha dos alunos, onde descobrem a Ciência fazendo 
Ciência, conforme já observadas por Costa (1988, p. 38), “onde todos os interessados pudessem trocar ideias e realizar reuniões, leituras e, acima de tudo, pesquisas dentro da própria comunidade".

Em uma observação geral, após as análises registradas em diário de campo, foi possível observar que em todas as partidas realizadas, os alunos rapidamente desenvolveram certa estratégia para que sua equipe pudesse avançar no tabuleiro o mais rapidamente possível e também conseguissem dificultar o progresso aos adversários. Assim, os jogadores sempre mantinham a atenção sobre as cores que estavam disponíveis aos outros grupos e articulavam entre si para propor uma melhor combinação de cores para prosseguirem de maneira eficaz pelo tabuleiro. Observou-se que as cartas de efeito tiveram um papel importante nas partidas, fornecendo aspectos desafiadores as equipes e motivação em relação à estratégia, pois elas conferiam as partidas um aspecto de surpresa ao jogo, e modificava constantemente as possibilidades de novas estratégias, o que auxiliou os alunos em estar sempre desenvolvendo esta habilidade de pensamento.

As análises das observações comportamentais dos alunos reforçaram a importância que o jogo apresentou para a revisão de conceitos, pois frequentemente os alunos se questionavam a respeito dos critérios sobre à teoria das cores, como elas eram formadas e seguiam argumentando com os membros da equipe amparados em suas explicações envolvendo os conceitos descritos e analisados anteriormente na sala de aula pelo professor. As frases ilustram estes momentos:

"Se agora eu tenho que colocar uma cor terciária, quer dizer que tem que ser uma mistura da secundária que eu tenho (no topo do bloco marrom do tabuleiro) com qualquer outra cor primária, né? Foi isso que eu me lembrei da aula” - ALUNO 2.

"Quando eu misturo uma cor terciária com o branco ou o preto, ela continua sendo terciária? Foi o que entendi” - ALUNO 15.

Observa-se que tanto o aluno 2 como o 15, nestes exemplos, recorrem a conceitos prévios discutidos anteriormente pelo professor na sala de aula. Seus argumentos tem relação com as discussões que foram levantadas naqueles momentos e pautadas em uma lógica formalizada em seu pensamento. Os resultados apresentados pela análise do 
diário de campo, reforçam o aspecto cognitivo que o jogo propicia, conforme $\mathrm{o}$ referencial teórico embasado por Vygotsky (2009). Segundo o autor, o desenvolvimento da espécie humana está baseado no aprendizado coletivo, e envolve a interferência, seja ela direta ou indireta, dos outros indivíduos e assim desenvolve a reconstrução do seu conhecimento através das experiências e dos significados vividos, a atividade lúdica proposta demonstrou esta relação social e sua implicação na aprendizagem. O conhecimento prévio também auxilia na formulação de uma explicação ao fenômeno observado, sua definição, e molda a uma maneira mais complexa para a resolução do problema, como aponta estudos já descritos por Glaser (1993), mas se mantendo atuais:

[...] a antiga hipótese pedagógica de que a aquisição de conhecimentos úteis começa com a aprendizagem fundamental, baseada na prática de habilidades básicas que exigem pouco raciocínio, prosseguindo para a aquisição de competência de nível superior, na qual a resolução de problemas desempenha um papel crescente, não é sustentável. Atualmente está claro que a capacidade de raciocinar não é posterior à aprendizagem básica, mas, pelo contrário, é parte da aquisição fundamental de conhecimentos e habilidades. (GLASER, 1993, p. 42, tradução nossa).

Criar concepções didáticas que auxiliam no pensamento lógico é importante para o seu avanço na aprendizagem e fortalecimento na resolução de problemas, como aponta Silva e Luna (2019):

[...] nos problemas que envolviam raciocínio lógico, as categorias que indicavam falta de percepção da inversão lógica (ou da falta dela) foram as que obtiveram maiores frequências nos erros. Em ambos os conjuntos, portanto, a dificuldade em solucionar problemas foi a maior geradora de erro nos participantes. (SILVA; LUNA, 2019, p. 1063).

Durante uma aplicação no Clube de Ciências, esta relação lógica de raciocínio foi verificada inúmeras vezes, por exemplo, quando em uma das rodadas um grupo que possuía uma carta de cor terciária com diferente tonalidade que se relacionava com as cores primárias do tabuleiro utilizaram as cartas de efeito Nerd e Mágico que estavam em sua mão para a resolução do problema. Como a equipe precisava de uma cor secundária e uma cor terciária, então com as cartas em sua mão, executou a seguinte jogada: com a carta Nerd pegaram a carta de efeito Artista, pegaram a cor secundária e, com a carta Mágico, recuperaram a carta Artista para pegar a cor terciária, e desta forma avançaram pelo tabuleiro mais rapidamente. A figura 6 ilustra o uso do jogo no Clube de Ciências. 


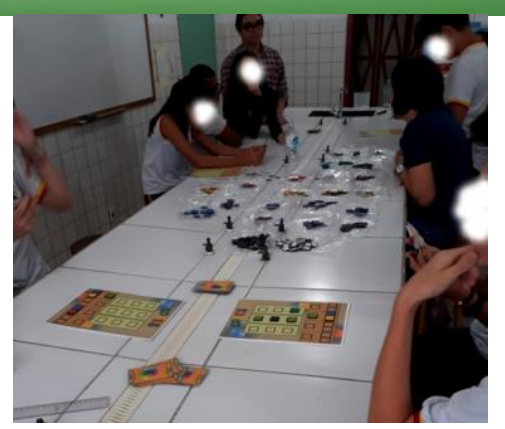

Figura 6 - Ilustração do emprego do jogo "Cores" realizado no Clube de Ciências.

Fonte: Próprios autores.

Um ponto a destacar é a importância que a parte gráfica do material pedagógico apresenta na divulgação da atividade e promoção da curiosidade. Na apresentação na Feira de Ciências, as cores chamativas do jogo incentivaram a curiosidade de muitos alunos que estavam observando a feira, corroborando ao trabalho de Benedetti-Filho et al. (2020). Após diversas partidas executadas, muitos comentários envolvendo a este respeito foram importantes para exemplificar que o impacto visual é um fator necessário para estes alunos nesta faixa de aprendizagem. Alguns comentários são descritos após análise nos registros do diário de campo:

\section{"Gostei dos desenhos das cartas" - Aluno 52. \\ “As peças estão muito bem feitas" - Aluna 39.}

Um ponto a destacar é que um dos alunos inclusive fez a pergunta de onde conseguimos comprar o jogo, querendo o endereço da loja, pois queria jogar com os seus colegas. A figura 7 ilustra alguns jogadores durante a realização da Feira de Ciências.

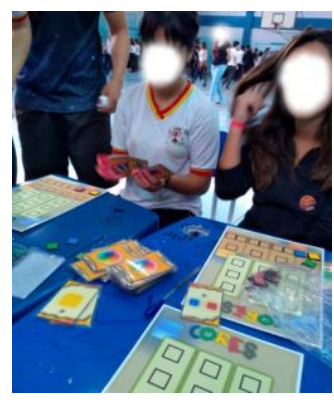

Figura 7 - Ilustração do emprego do jogo “Cores” realizado na Feira de Ciências.

Fonte: Próprios autores. 
O emprego de uma metodologia didática mais informal, descontraída é importante para a motivação dos alunos e o desenvolvimento de habilidades muitas vezes não exploradas na maioria dos momentos de aprendizagem. $\mathrm{O}$ uso de metodologias ativas contribui para o engajamento dos alunos e possibilita seu maior envolvimento em grupo, facilitando o seu processo de aprendizagem, tanto para ler, escrever, mas de forma mais eficiente em relação ao perguntar, discutir e resolver os problemas desenvolvidos em projetos.

É importante que o aluno possa realizar tarefas mentais em um nível sempre mais avançado, para promover o seu aprendizado, e nestes exercícios, a análise, a síntese e a avaliação, são ferramentas metodológicas que devem promover uma aprendizagem ativa aos alunos, o qual faz com que pensem sobre o que estão desenvolvendo, executando a tarefa (BONWELL; EISON, 1991; SILBERMAN, 1996). Uma das maneiras de aumentar esta evolução é a aprendizagem entre pares, no qual a atividade lúdica proposta teve tal objetivo alcançado, pois o aluno teve uma atividade ativa e interativa entre si ao longo de toda a realização do jogo.

As observações no diário de campo ilustraram, após análise, que os alunos procuraram explicar, entre os integrantes das equipes, os conceitos estudados previamente e assim realizou tarefas para a sua solução. O uso deste método de ensino interativo proposto visou incentivar os alunos a aprender através das fontes primárias e das interações com os demais colegas, a construção de um novo conhecimento, este adquirido conjuntamente baseado em discussões e interpretações dos fatos ocorridos no momento das disputas durante o jogo.

Os resultados obtidos, este sendo interpretativos em relação ao comportamento dos alunos, demonstrou que a aprendizagem baseada em jogos, realizou um aprendizado mais descontraído aos alunos, no ponto de vista relacionado com as discussões e a interação social, pois os mesmos puderam expor suas ideias sem os olhares centrados quando a discussão sobre determinado assunto ocorre em sala de aula. Este espaço de descontração, fez com que os alunos, tivessem um comportamento mais sujeito a explorar seus argumentos, sem a cobrança de um acerto ou erro, como geralmente ocorre na sala de aula. 
Esta discussão sadia que ocorreu nas equipes fez com que todos os alunos pudessem participar e dialogar sobre suas hipóteses de movimento no momento do jogo e desta forma aprender a trabalhar em equipe, a respeitar a opinião da maioria, a ouvir, a esperar sua vez de expor, etc. Foi observado que estas questões comportamentais são importantes para que o aprendizado seja mais bem consolidado, mesmo em outros conteúdos, para uma aprendizagem efetiva e não mecânica ou decorativa.

\section{CONCLUSÃO}

As análises do diário de campo para a pesquisa desenvolvida através do emprego de uma atividade lúdica demonstrou ser um eficiente instrumento metodológico para o incentivo às discussões em grupo com respeito à teoria das cores. A montagem do tabuleiro empregando uma arte gráfica simples e com um visual impactante, contribuiu para atingir os objetivos da proposta, incentivando os alunos a terem curiosidade pelo jogo e assim promover a divulgação científica quando utilizado na Feira de Ciências.

Esta metodologia utilizada para a revisão dos conceitos trabalhos previamente pelo professor em sala de aula foi totalmente atingida, principalmente quando analisado os resultados nas discussões sobre a teoria das cores no Clube de Ciências. A interação social e as habilidades para um trabalho em equipe, nas resoluções de problemas, foi outro motivo importante que a metodologia atingiu. Os resultados das interpretações comportamentais nos momentos em que os alunos efetuaram o uso do jogo comprovou a proposta inicial idealizada pelos pesquisadores, e assim contribuindo para o pensamento lógico dos alunos nas resoluções dos desafios encontrados durante as partidas.

\section{REFERÊNCIAS}

ALVES, T. C. R.; COSTA, M. F.; SOUSA, C. C. Tabuleiro de genes: uma ferramenta pedagógica para o ensino de biologia. Revista Prática Docente, v. 5, n. 2 , p. 1093-1110, 2020.

BARROS, L. R. M. A cor no processo criativo: um estudo sobre a Bauhaus e a teoria de Goethe. $2^{\mathrm{a}}$ ed. São Paulo: Editora Senac, 2007. 
BENEDETTI-FILHO, E.; BENEDETTI, L. P. S. Emprego de atividades lúdicas no ensino de química. Sorocaba: Editora Cidade, 2015.

BENEDETTI-FILHO, E.; CAVAGIS, A. D. M.; LIMA, M. H.A.; BENEDETTI, L. P. S. Fuga! um jogo de tabuleiro desenvolvido para a revisão de conceitos de química. Revista Insignare Scientia, v. 3, n. 1, p. 77-95, 2020.

BOGDAN, R.; BIKLEN, S. Investigação qualitativa em educação. Porto: Porto Editora, 2000.

BONWELL, C.; EISON, J. Active learning: creating excitement in classroom. $1^{\mathrm{a}}$ ed. Washington: The George Washington University, School of Education and Human Development, 1991.

BROUGÈRE, G. Jogo e educação. Porto Alegre: Artmed Editora, 2002.

COSTA, A. Clubes de Ciências "Pequeno Príncipe" uma realidade na área rural. Revista PROCRIS, v.1, n1, 1988.

COSTA, E. A.; DUARTE, R. A. F.; GAMA, J. A. S. A gamificação da botânica: uma estratégia para a cura da "guerra botânica". Revista Insignare Scientia, v. 2, n. 4, p. 7999, 2019.

FARINA, M. Psicodinâmica das cores em comunicação. São Paulo: Edgard Blücher, 1986.

GLASER, R. Advances in instructional Psychology. Vol. 4, Hillsdade: Lawrence Eribaum, 1993.

GODOY, A. S. Introdução à pesquisa qualitativa e suas possibilidades. Revista de Administração de Empresas, v. 35, n. 2, p. 57-63, 1995.

GUIMARÃES, L. A cor como informação: a construção biofísica, linguística e cultural da simbologia das cores. $2^{\mathrm{a}}$ ed. São Paulo: Annablume, 2002.

KISHIMOTO, T. M. O jogo e a educação infantil. São Paulo: Pioneira, 1994.

KRASILCHIK, M. P. Prática de ensino de biologia. 4ª ed. São Paulo: Edusp, 2008.

LEITE, M. A. S.; SOARES, M. H. F. B. Jogo pedagógico para o ensino de termoquímica em turmas de educação de jovens e adultos. Revista Química Nova na Escola, v. 43, n. 3, p. 227-236, 2020.

MELLO, A. C. K. A. de. O grupo focal como fonte de coleta de dados em pesquisas qualitativas. In: VII ENCONTRO DO GRUPO DE PESQUISA "EDUCAÇÃ̃, ARTE E INCLUSÃO”, 2011. Anais..., 2011. 
PEDROSA, I. Da cor a cor inexistente. Rio de Janeiro: Léo Cristiano Editorial, 1989.

SILVA, S. O. A.; LUNA, S. V. Correlação entre o raciocínio lógico e o raciocínio matemático em crianças escolarizadas. Bolema, v. 33, n. 65, p. 1047-1066, 2019.

SILBERMAN, M. Active learning: 101 strategies do teach any subject. Massachusetts: Ed. Allyn and Bacon, 1996.

SOARES, M. H. F. B. jogos e atividades lúdicas para o ensino de química. $2^{\text {a }}$ ed. Goiânia: Kelps, 2015.

VYGOTSKY, L. S. A construção do pensamento e da linguagem. $2^{a}$ ed. São Paulo: Martins Fontes, 2009.

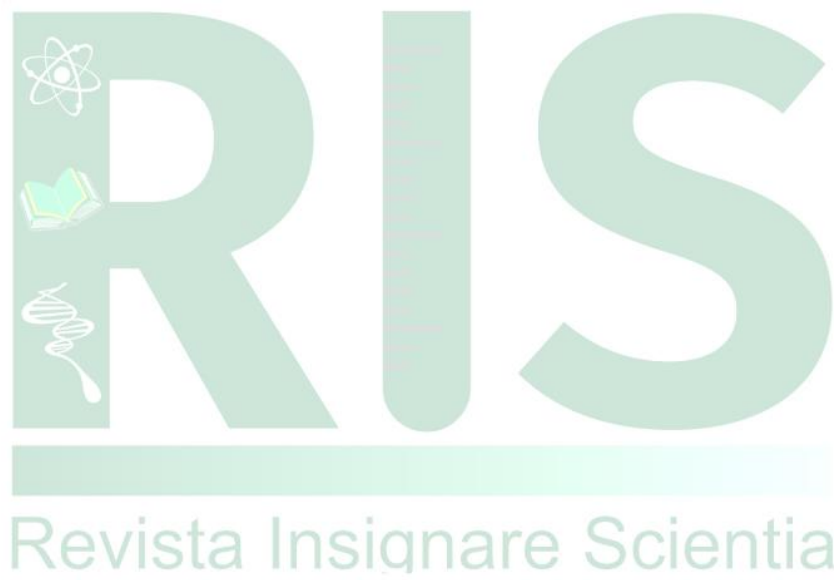

